\title{
Design and Comparative Study of Pin feed and Line feed Microstrip Patch Antenna for X-band Applications
}

\author{
${ }^{1}$ Rajeshkumar V, ${ }^{2}$ Priyadarshini K, ${ }^{3}$ Glory Devakirubai D, ${ }^{4}$ Ananthi C, ${ }^{5}$ Snekha P \\ 1,2,3,4,5 Department of Electronics and Communication Engineering, \\ 1,2,3,4,5 Karpagam Institute of Technology, Coimbatore, Tamilnadu, India
}

\begin{abstract}
This research work presents design, simulation and comparison of microstrip patch antenna designed using different feed techniques. The Microstrip feed techniques are microstrip line feed, inset feed, coaxial feed, aperture coupled feed and proximity coupled feed. We are chosen to compare co-axial feed and microstrip line feed due to the advantage that it can be easily fabricated and simplicity in modelling as well as impedance matching. The microstrip patch antenna is designed and simulated using high frequency simulation software FEKO and it is designed to operate in X-band frequency range $(8 \mathrm{GHz}-12 \mathrm{GHz})$. These antennas are designed using taconic dielectric substrate with the permittivity $\varepsilon_{\mathrm{r}}=2.2$. In this analysis, we have compared the antenna parameters such as gain, impedance, reflection coefficient, VSWR and further the performance of these two feed techniques discussed. The antenna has been designed for the range 9-11 $\mathrm{GHz}$; hence this antenna is highly suitable for X-band applications such as satellite communication, radar, medical applications, and other wireless systems.
\end{abstract}

\section{General Terms}

Microstrip Patch Antenna, Line Feed, Pin Feed

\section{Keywords}

X-Band, Return Loss, Impedance, Radiation Pattern, VSWR

\section{INTRODUCTION}

Modern wireless communication system requires low profile, light weight, high gain, and simple structure antennas to assure reliability, mobility, and high efficiency characteristics $[1,2]$. The key features of a microstrip antenna are relative ease of construction, light weight, low cost and either conformability to the mounting surface or, an extremely thin protrusion from the surface $[2,3]$. This antenna provides all of the advantages of printed circuit technology. These advantages of microstrip antennas make them popular in many wireless communication applications such as satellite communication, radar, medical applications, etc [3]. Choosing the design parameters (dielectric material, height and frequency, etc) is important because antenna performance depends on these parameters. Radiation performance can be improved by using proper design structures. The use of high permittivity substrates can miniaturize microstrip antenna size. Thick substrates with lower range of dielectric offer better efficiency and wide bandwidth but it requires larger element. And it depends on the feeding technique the parameters like VSWR return loss bandwidth will vary [1].
This research provides a way to choose the effective feeding technique between transmission lines and Microstrip patch antenna. It also compares the characteristics of pin feed and line feed techniques. By comparing the antenna parameters the best feeding technique will be selected for the design of microstrip patch array antenna. These designed antennas are potential candidate for the X-band wireless applications due to the simplicity in structure, ease of fabrication, high gain and high efficiency [4].Various parameters of the microstrip patch antennae, design considerations, performance of different feed techniques are discussed in the subsequent sections.

\section{MICROSTRIP PATCH ANTENNA}

Microstrip antenna consists of very small conducting patch built on a ground plane separated by dielectric substrate. The patch is generally made of conducting material such as copper or gold and can take any possible shape [1]. The radiating patch and the feed lines are usually photo etched on the dielectric substrate. The conducting patch, theoretically, can be designed of any shape, however rectangular and circular configurations are the most commonly used $[1,6]$. Some of the other configurations used are complex to analyze and require large numerical computations. In its most fundamental form, a microstrip patch antennae consist of a radiating patch on one side of a dielectric substrate which has a ground plane on the other side [1] is illustrated in figure 1.

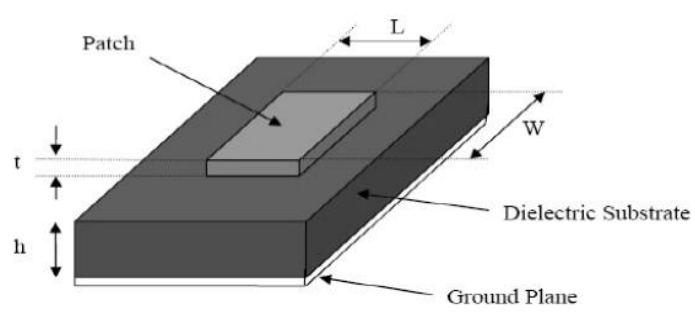

Fig 1: Structure of Microstrip Patch Antenna

Microstrip patch antennae radiate primarily because of the fringing fields between the patch edge and the ground plane. For a rectangular patch, the length $L$ of the patch is usually $0.3333 \lambda 0<L<0.5 \lambda 0$, where $\lambda 0$ is the free space wavelength $[1,9]$. The patch is selected to be very thin such that $t<<\lambda 0$ (where $t$ is the thickness of patch). The height $h$ of the dielectric substrate is usually $0.003 \lambda 0 \leq h \leq 0.05 \lambda 0$. The dielectric constant of the substrate is typically in the range 1.2 $\leq \varepsilon r \leq 12$. 


\section{FEED TECHNIQUES}

Microstrip patch antennae can be fed by a variety of different methods [1]. The four most popular feed techniques used for the microstrip patch are

- $\quad$ Microstrip line feed

- $\quad$ Pin feed

- $\quad$ aperture coupling

- $\quad$ proximity coupling

In this paper line feed and pin feed schemes are analyzed and compared using FEKO.

\subsection{Microstrip Line Feed}

In this type of feeding technique, a conducting strip connected directly to the edge of the microstrip patch. The conducting strip is smaller in width as compared to the patch and this kind of feed arrangement has the advantage that the feed can be on the same substrate to provide a planar structure $[6,7]$. This is an easy feeding scheme, since it provides ease of fabrication and simplicity in modeling as well as impedance matching. However as the thickness of the dielectric substrate being used, increases, surface waves and spurious feed radiation also increases, which hampers the bandwidth of the antenna [7]. The feed radiation also leads to undesired cross polarized radiation. Figure 2 shows a with microstrip line feed from the side of the patch.

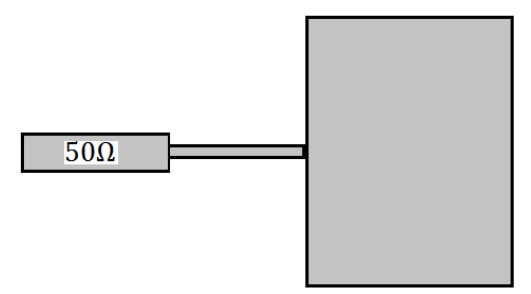

Fig 2: Typical Microstrip Line Feed

However, this method of feeding is very widely used because it is very simple to design and analyze, and very easy to manufacture. Figure 3 shows rectangular patch antenna with microstrip line feed.

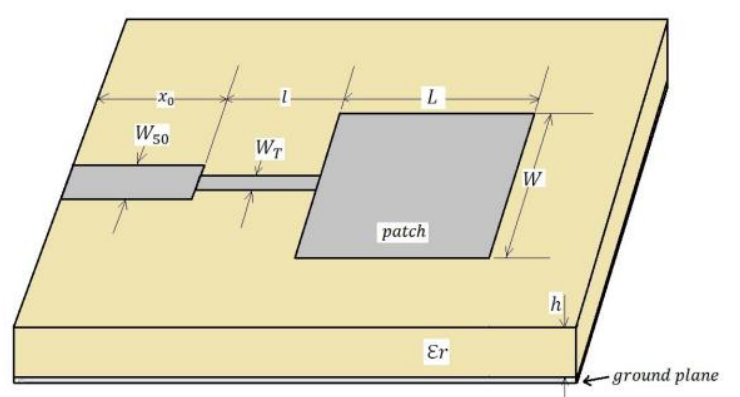

Fig 3: Microstrip Patch Antenna with Line Feed

\subsection{Coaxial Feed (Pin Feed)}

The Coaxial feed or pin feed is a very common technique used for feeding Microstrip patch antennas. The inner conductor of the coaxial connector extends through the dielectric and is soldered to the radiating patch, while the outer conductor is connected to the ground plane. The main advantage of this type of feeding scheme is that the feed can be placed at any desired location inside the patch in order to match with its input impedance [7, 10]. This feed method is easy to fabricate and has low spurious radiation. However, its major disadvantage is that it provides narrow bandwidth and is difficult to model slice a hole has to be drilled in the substrate and the connector protrudes outside the ground plane, thus not making it completely planar for thick substrates $(h>0.02 \lambda 0)[1]$. Also, for thicker substrates, the increased probe length makes the input impedance more inductive, leading to matching problems [7, 8].

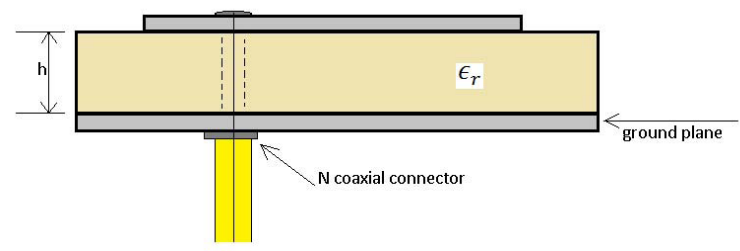

Fig 4: Microstrip Patch Antenna with Coaxial Feed

\section{DESIGN CONSIDERATIONS}

Microstrip patch antenna consists of very thin metallic strip (patch) placed on ground plane where the thickness of the metallic strip is restricted by $\mathrm{t}<<\lambda 0$ and the height is restricted by $0.0003 \lambda 0 \leq \mathrm{h} \leq .05 \lambda 0$. The microstrip patch is designed so that its radiation pattern maximum is normal to the patch. For a rectangular patch, the length $\mathrm{L}$ of the element is usually $\lambda 0 / 3<\mathrm{L}<\lambda 0 / 2[1,6]$.

\subsection{Design Procedure for Patch Antenna}

The Performance of the microstrip patch antenna depends on its resonant frequency, dimension. Depending on the dimension, the operating frequency, radiation efficiency, directivity, return loss are influenced. For an efficient radiation, the practical width of the patch can be calculated by using the following.

$$
W=\frac{1}{2 f_{r} \sqrt{\mu_{0} \epsilon_{0}}} \times \sqrt{\frac{2}{\varepsilon_{r}+1}}
$$

And the length (L) of the antenna becomes,

Where,

$$
L=\frac{1}{2 f_{r} \sqrt{\varepsilon_{e f f}} \sqrt{\mu_{0} \varepsilon_{0}}}-2 \Delta L
$$

$$
\begin{gathered}
\varepsilon_{\text {eff }}=\frac{\varepsilon_{r}+1}{2}+\frac{\varepsilon_{r}-1}{2 \sqrt{1+12 \frac{h}{W}}} \\
\Delta L=\frac{(\text { rreff }+0.3)\left(\frac{w}{h}+0.264\right)}{(\text { reff }-0.258)\left(\frac{w}{h}+0.8\right)} * 0.412 h
\end{gathered}
$$

Where $\lambda$ is the wave length, $f_{r}$ is the resonant frequency, $L$ and $\mathrm{W}$ are the length and width of the patch element respectively and $\varepsilon_{\mathrm{r}}$ is the dielectric constant. Antenna that has been designed to cover the frequency range 9- $11 \mathrm{GHz}$. By using the above formulae the width is found to be 11.9 and height of the patch is found to be 9.1.By Using these results the microstrip patch antenna have been designed using the simulation software FEKO which is shown below. 


\subsection{Design Procedure for Line Feed}

The quarter wavelength transformer method is used to match the impedance of the patch element with the transmission line. The designed microstrip patch antenna using FEKO is shown in the Figure 5.

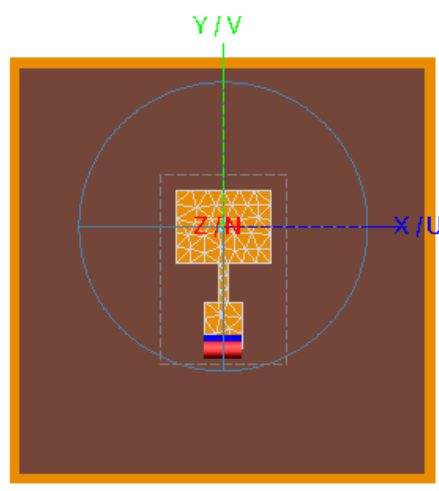

Fig 5: Line Feed Technique

The following formulae were used to design feeding element and transmission line:

Characteristic impedance of the patch can be found by

$$
Z_{a}=90 \frac{\varepsilon_{\mathrm{r}}^{2}}{\varepsilon_{\mathrm{r}}-1}\left(\frac{L}{W}\right)^{2}
$$

Impedance of transition section:

$$
\mathrm{Z}_{\mathrm{T}}=\sqrt{50+\mathrm{Z}} \mathrm{a}
$$

Width of transition line $\mathrm{W}_{\mathrm{T}}$ :

$$
\mathrm{Z}_{\mathrm{T}}=\frac{60}{\sqrt{\varepsilon_{\mathrm{r}}}} \ln \left(\frac{8 \mathrm{~d}}{\mathrm{~W}_{\mathrm{T}}}+\frac{\mathrm{W}_{\mathrm{T}}}{4 \mathrm{~d}}\right)
$$

Length of transition line:

$$
l=\frac{\lambda}{4}=\frac{\lambda_{0}}{\sqrt{\varepsilon_{e f f}}}
$$

Width of $50 \Omega$ microstrip transmission line:

$$
Z_{0}=\frac{120 \pi}{\sqrt{\varepsilon_{e f f}\left(1.393+\frac{W}{h}+\frac{2}{3} \ln \left(\frac{W}{h}+1.444\right)\right)}}
$$

Where $\mathrm{Z}_{0}=50 \Omega$

Length of the microstrip transmission line

$$
R_{\text {in }(x=0)}=\frac{Z_{0}}{Z_{T}}=\operatorname{Cos}^{2}\left(\frac{\pi}{L}\right) x_{0}
$$

\subsection{Design Procedure for Pin Feed}

The pin feed is designed at the distance of $8.9 \mathrm{~mm}$ and the radius is $0.65 \mathrm{~mm}$. Figure 6 shows the patch antenna designed using FEKO with pin feed technique.

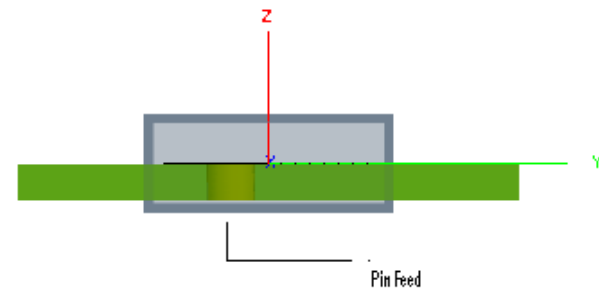

Fig 6: Pin Feed Technique

\section{SIMULATION RESULTS AND DISCUSSION}

The software used to model and simulate the microstrip patch antennae is High Frequency Simulation Software - FEKO Suite 6.0 version. It has been widely used in the design of MICs, RFICs, patch antennae, wire antennae, and other $\mathrm{RF} /$ wireless antennae designs [5]. It can be used to determine and plot the reflection parameters, Voltage Standing Wave Ratio (VSWR), current distributions as well as the radiation patterns. Figure 5, 6 shows the edge feed and Pin feed microstrip patch antennae designed using FEKO suite 6.1 version.

\subsection{Return Loss}

A frequency range of $9-11 \mathrm{GHz}$ is chosen as the resonant frequency which is suitable for $\mathrm{x}$-band applications. Figure 7 shows return loss plot for the line feed technique. Generally the return loss should be in the range of $-4.96 \mathrm{~dB}$ to $-25.21 \mathrm{~dB}$ [10]. From the figure it is clear that the return loss at the resonant frequency $9.7 \mathrm{GHz}$ is $-17 \mathrm{~dB}$.

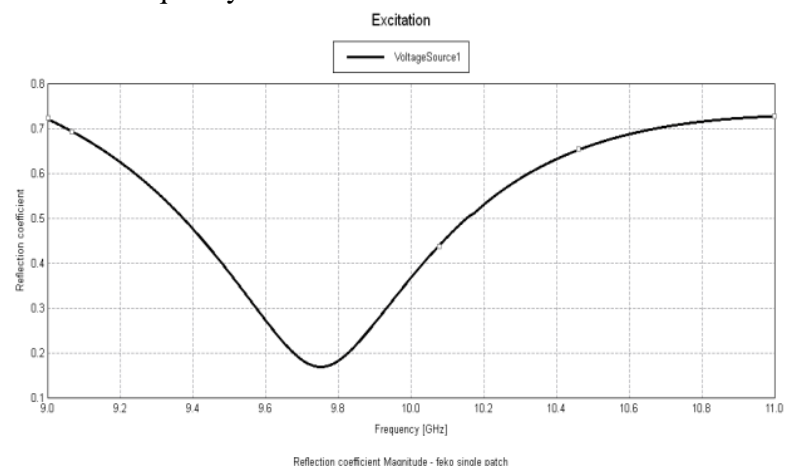

Figure 7: Return loss for Line Feed

The figure below shows the return loss plot for pin feed technique. The return loss achieved here at the resonant frequency $9.85 \mathrm{GHz}$ is $-13.5 \mathrm{~dB}$.

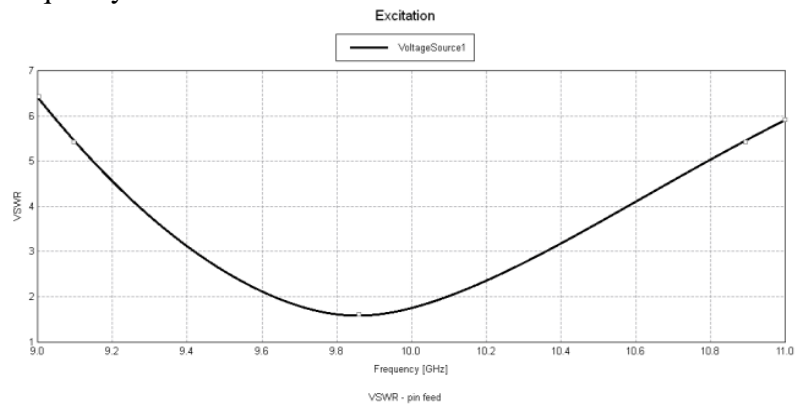

Figure 8: Return loss for Pin Feed 


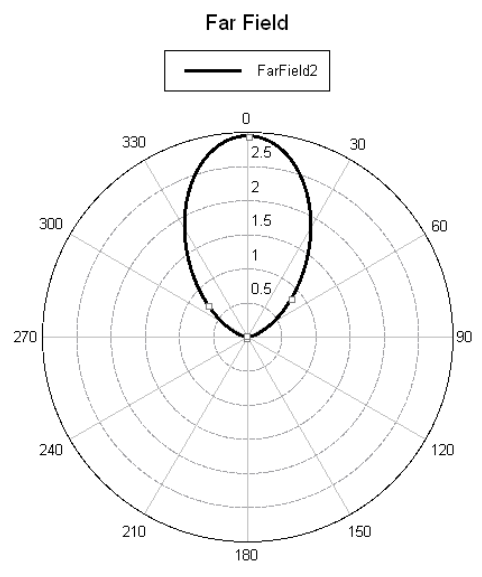

Total Gain (Frequency $=9.75 \mathrm{GHz}_{i}$ Phi $=0$ deg) - feko single patch

\section{Figure 9: Gain for Line Feed}

Hence, it is clear that the losses associated with pin feed is more compared to line feed technique.

\subsection{Radiation Pattern Plots}

Since a microstrip patch antenna radiates normal to its patch Surface, the elevation pattern for $\varphi=0$ and $\varphi=90$ degrees would be important. Figure 9 and Figure 10 shows the gain plot for line feed technique and Pin feed technique respectively.

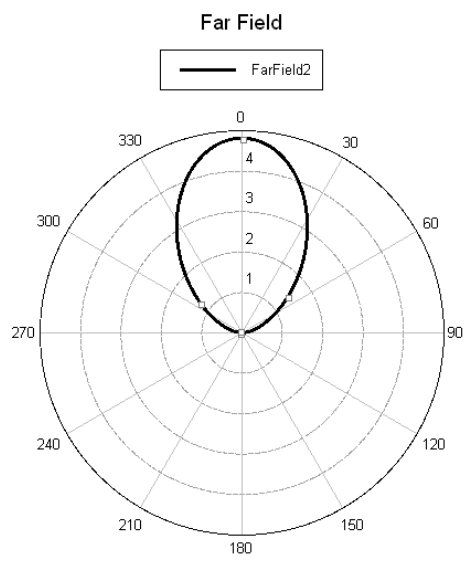

Total Gain (Frequency $=9.875 \mathrm{GHz} ;$ Phi $=0$ deg) - pin feed

Figure 10: Gain for Pin Feed

From the above figures it is clear that gain is maximum for pin feed technique and its gain $4.5 \mathrm{~dB}$. Generally the gain should be above $6 \mathrm{~dB}$ which will be achieved when we use array of antenna.

\subsection{Impedance}

The theory of maximum power transfer states that for the transfer of maximum power from a source with fixed internal impedance to the load, the impedance of the load must be the same of the source. The following are the impedance plot. Figure 11 and Figure 12 shows impedance plot for the line feed and pin feed technique respectively.

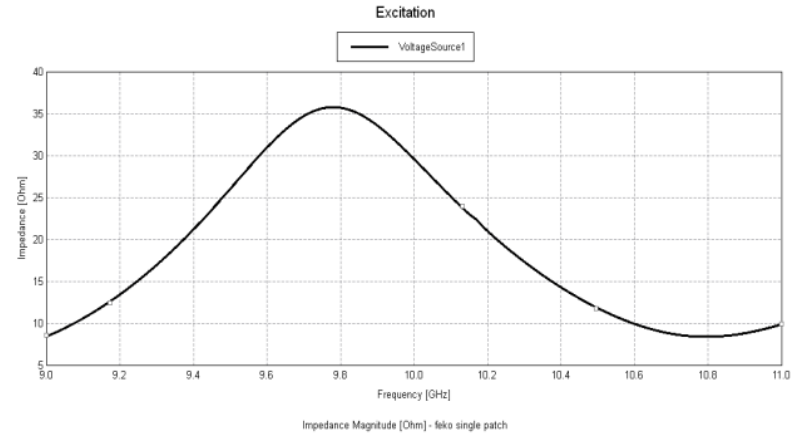

Figure 11: Impedance for Line Feed

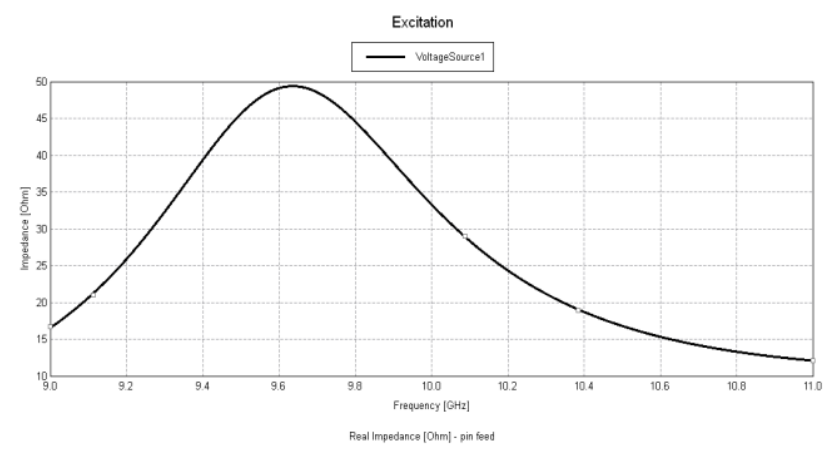

Figure 12: Impedance for Pin Feed

From the above figures we can infer that impedance is perfectly matched in case of pin feed at the resonant frequency.

\subsection{VSWR}

When a transmitter is connected to an antenna by a feed line, the impedance of the antenna and feed line must match exactly for maximum possible energy transfer from the feed line to the antenna. When an antenna and feed line do not have matching impedances, some of the electrical energy cannot be transferred from the feed line to the antenna. Energy not transferred to the antenna is reflected back towards the transmitter. It is the interaction of these reflected waves with forward waves which causes standing wave patterns. Ideally, VSWR must lie in the range of 1-2 [1].

Figure 13 and Figure 14 shows the VSWR plot for Line feed and pin feed respectively. It is clear that in both cases the VSWR value lies in the acceptable range.

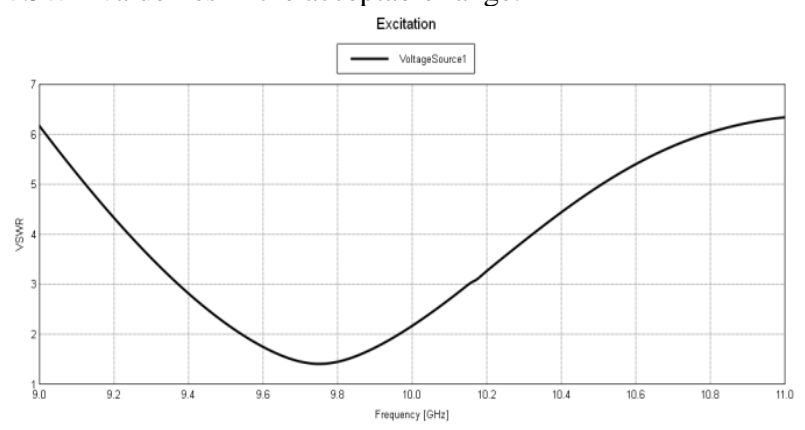

Figure 13: VSWR for Line Feed 


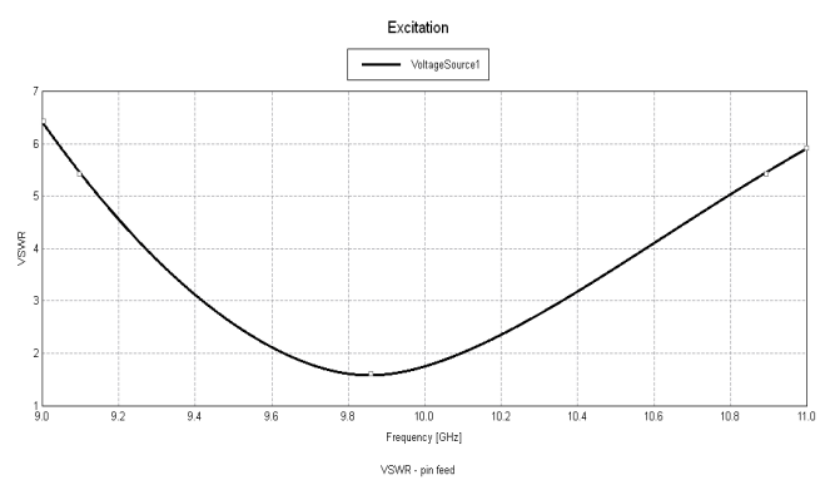

Figure 14: VSWR for Pin Feed

Table 1 shows the comparative for line feed and Pin feed technique which gives simulated values for the paramaters like return loss, gain,impedane,VSWR. In which the pin feed technique has high gain, good impedance and high VSWR.

Table.1. Performance Comparison of Line Feed and Pin Feed technique

\begin{tabular}{|c|c|c|}
\hline $\begin{array}{c}\text { Patch } \\
\text { parameters }\end{array}$ & Line feed & Pin feed \\
\hline Return loss & $-16.5 \mathrm{~dB}$ & $-13.5 \mathrm{~dB}$ \\
\hline Gain & $2.6 \mathrm{~dB}$ & $4.6 \mathrm{~dB}$ \\
\hline Impedance & $38.7 \mathrm{ohm}$ & $50 \mathrm{ohm}$ \\
\hline VSWR & 1.2 & 1.5 \\
\hline
\end{tabular}

\section{CONCLUSION}

The unique feature of this microstrip antenna is its simplicity to get higher performance. In many applications essentially in radar and satellite communication, it is necessary to design antennas with very high directive characteristics to meet the demand of long distance communication The line feed and pin feed microstrip patch antennae has been designed and simulated using high frequency simulation software FEKO. The simulation results show that the pin feed excitation technique provides more gain and perfect impedance matching compared to line feed excitation technique. Also the main advantage of this feeding technique is that feed can be given anywhere inside the patch which makes easier fabrication compared to edge feed technique In future microstrip patch antenna array will be designed for the same operating frequency range in order to achieve the maximum gain which is highly suitable for $\mathrm{x}$-band applications.

\section{REFERENCES}

[1] Kashwan K R ,Rajeshkumar V, Gunasekaran T and Shankar Kumar K R, "Design and Characterization of Pin Fed Microstrip Patch Antennae", IEEE proceedings of FSKD'2011

[2] M. T. I. Huque, et al., "Design and Simulation of a Lowcost and HighGain Microstrip Patch Antenna Arrays for the X-band Applications," in International Conference on Network Communication and Computer-ICNCC 2011, New Delhi, India., March 21-23, 2011.

[3] N. Kanniyappan, Dr.R. Indra Gandhi, "Design and Analysis of Microstrip Patch Antenna Feeding Techniques", IEEE proceedings of International Conference on Computational Intelligence and Computing Research'2011

[4] Prof. Mahesh M. Gadag, Mr. Dundesh S. Kamshetty, Mr. Suresh L.Yogi, Mr. Vinayak C. D, "Design and Comparative Study of Different Feeding Mechanisms for Microstrip Antenna for Wireless Communication", IEEE proceedings of International Conference on Computational Intelligence and Computing Research'2011.

[5] FEKO Suite 6.1 User manual, EM Software and Systems S.A Pvt Ltd, 2010.

[6] C. A. Balanis, 1982, Antenna Engineering, 2nd ed., Willey.

[7] Ahmed Fatthi Alsager Design and Analysis of Microstrip Patch Antenna Arrays thesis comprises 30 ECTS credits and is a compulsory part in the Master of Sciencewith a Major in Electrical Engineering- Communication and Signal processing.Thesis No. 1/2011

[8] T. A. Millikgan, 2007, "Modern Antenna Design", 2nd ed., IEEE Press,JohnWiley \& Sons inc.

[9] R. Garg, P. Bhartia, I. Bahl, A. Ittipiboon, 2001 "Microstrip Antenna Design Handbook", Artech House inc.

[10] Md. Tanvir Ishtaique-ul Huque1, Md. Kamal Hosain2, Md. Shihabul Islam3, and Md. Al-Amin Chowdhury4 "Design and Performance Analysis of. Microstrip Array Antennas with Optimum Parameters for XbandApplication”, IEEE proceedings of IJACSA'2011. 